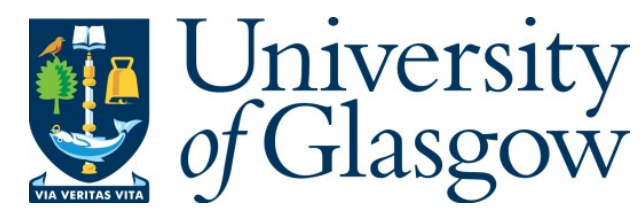

Smith, A . ., Cameron, S.O., B agg, J., and K ennedy, D. (2001) Management of needlestick injuries in general dental practice. B ritish Dental J ournal, 190 (12). pp. 645-650. ISSN 0007-0610

Copyright $\odot 2001$ B ritish Dental J ournal

A copy can be downloaded for personal non-commercial research or study, without prior permission or charge

Content must not be changed in any way or reproduced in any format or medium without the formal permission of the copyright holder(s)

When referring to this work, full bibliographic details must be given

http://eprints.gla.ac.uk/186/

Deposited on: 30 J uly 2010

Enlighten - Research publications by members of the U niversity of Glasgow http://eprints.gla.ac.uk 


\title{
Management of needlestick injuries in general dental practice
}

\author{
A. J. Smith, ' S. O. Cameron, ${ }^{2}$ J. Bagg, ${ }^{3}$ and D. Kennedy, ${ }^{4}$
}

\begin{abstract}
The objective of this paper is to advise on the development of practical policies for needlestick injuries in general dental practice. Policies for dealing with occupational exposure to chronic blood borne viruses, namely, hepatitis B, C and HIV are evolving. This article was particularly prompted by recent changes in post exposure prophylaxis for HIV infection. A flow chart is also included which should be of possible use in general dental practice. Needlestick injuries are of increasing concern to healthcare workers. Succesful prophylaxis requires careful planning in advance. Whilst all practices should have a policy for sharps injuries, prevention of needlestick injuries remains the best policy.
\end{abstract}

$\mathrm{H}$ ealthcare workers (HCW) including dental staff, may be exposed to bloodborne viruses (BBV) carried in blood, oral fluids and tissues. Hepatitis B virus (HBV), hepatitis $\mathrm{C}$ virus (HCV) and human immunodeficiency virus (HIV) are the principal blood borne pathogens of concern to dental staff.

In the UK, HBV currently affects less than $0.1 \%$ of the population, although carriage rates are higher in risk groups, such as intravenous drug users. HBV is the most infectious of the three viruses with a $30 \%$ risk of seroconversion following a sharps injury involving a high risk carrier to a susceptible individual. HBV has frequently been transmitted in dental practice, ${ }^{1-4}$ although infection rates have declined considerably in dental staff as a consequence of immunisation and improvements in infection control practices. ${ }^{5}$ However, there is evidence in the recent literature that there are significant groups of healthcare workers worldwide who do not receive appropriate hepatitis B vaccination. ${ }^{6-8}$ Within general dental prac-

${ }^{1}$ Lecturer/Hon Sp Registrar Microbiology ${ }^{3}$ Professor of Clinical Microbiology, Infection Research Group, Glasgow Dental Hospital \& School, 378 Sauchiehall Street, Glasgow; ${ }^{2}$ Consultant Clinical Scientist, Regional Virus Laboratory, Gartnavel General Hospital, Glasgow; ${ }^{4}$ Consultant Physician in Infectious Diseases, Infection, Tropical Medicine and Counselling Service, Brownlee Centre, Gartnavel General Hospital, Glasgow

${ }^{*}$ Correspondence to: Dr A J Smith email:a.smith@dental.gla.ac.uk

REFEREED PAPER

Received 24.08.00; Accepted 04.01.01

(C) British Dental Journal 2001; 190: 645-650 tice in the United Kingdom, hepatitis B immunisation is mandatory, ${ }^{9}$ but there are few formal checks on compliance. Dental personnel who either have not completed a course of hepatitis B immunisation, or who are non-responders to the vaccine, are at significant risk of infection. For such individuals, the possible need for prophylaxis with hepatitis B immunoglobulin following a needlestick injury must not be overlooked.

$\mathrm{HCV}$ prevalence in the UK is estimated at $0.5-1 \%$ in the general population. However, in risk groups, such as intravenous drug users, antibody prevalence can be up to $85 \%$ with approximately $60 \%$ carrying the virus. ${ }^{10}$ In the US, a review of published studies in HCWs who received a needlestick injury from an anti-HCV positive source estimated the risk of transmission to be $1.8 \% .{ }^{11}$ More recently the risk of transmission was shown to be greater if the source patient were positive for $\mathrm{HCV}$ RNA, with no transmission occurring

\section{In brief}

- This paper highlights the management of needlestick injuries in general dental practice by use of two case scenarios.

- All dental healthcare workers should be aware of the risks from blood borne

- All practices should have a policy for the management of a sharps injury, however, prevention of injuries remains the best policy. viruses associated with sharps injuries.

$\begin{array}{ll}\text { Glossary of abbreviations } \\ \text { BBV } & \text { Blood borne virus } \\ \text { EPP } & \text { Exposure prone procedure } \\ \text { HBV } & \text { Hepatitis B virus } \\ \text { HBs } & \text { Hepatitis B surface antigen } \\ \text { HCV } & \text { Hepatitis C virus } \\ \text { HCW } & \text { Healthcare worker } \\ \text { HIV } & \text { Human immunodeficiency } \\ & \text { virus } \\ \text { IVDU } & \text { Intravenous drug user } \\ \text { PEP } & \text { Post exposure prophylaxis } \\ \text { RIDDOR } & \text { Reporting of Injuries, } \\ & \text { Diseases and Dangerous } \\ & \text { Occurrences Regulations }\end{array}$

from HCV RNA negative sources. ${ }^{12}$ The prevalence of HCV in dental staff has varied from 0 to $6.2 \% .^{13-17}$

HIV prevalence is now estimated at 30,000 in the UK. ${ }^{18}$ The risk of HIV transmission following a single exposure to a contaminated sharps device has been determined from various prospective and crosssectional studies in HCW. Of over 6,955 occupational exposures to sharps contaminated with HIV infected blood there were 22 seroconversions or $0.32 \% .^{19,20}$ There was a lower risk from mucocutaneous exposure $(0.03 \%) .{ }^{19,20}$ Many of the body fluids from which HIV has been isolated, such as saliva, have not as yet been implicated in occupational transmission. Furthermore the nature of injuries sustained in dental practice tend to be of relatively low risk (Table 1). Thus the risk of HIV infection following a dental sharps injury is low.

\section{First aid measures}

There are no data on the effect of first aid treatment in reducing the risk of BBV transmission following occupational exposure. Nevertheless we recommend that for percutaneous (needlestick/sharpobject) injuries the wound should be washed (and not scrubbed) for several minutes with soap and water, or a disinfectant with known activity against BBVs (10\% iodine solution or chlorine compounds). Pressure above the wound to induce bleeding from the contaminated injury should also be performed. For a mucous membrane exposure we recommend copious 
irrigation with tap water, sterile saline or sterile water for several minutes.

The rationale behind such first aid measures is to reduce the bioburden below the threshold of an infectious dose. Therefore dilution with water may, of itself, lower the number of organisms below that required to initiate infection. The application of disinfectant solutions may further help. It is very important not to scrub the injury since this may inoculate the virus into the tissues. Downstream pressure above the wound may help to extrude infectious material. These procedures are of equal relevance to all blood borne viruses.

\section{New policies on the management of HIV associated occupational exposure}

Risk assessment

The first documented case of HIV seroconversion following a needlestick occurred in $1984 .^{21}$ Since then, surveillance of occupationally acquired HIV infection has been established in several countries. Good epidemiological data are important for accurate interpretation of risk analysis so that prophylaxis may be appropriately instituted. Occupational risk of HIV infection depends on the population prevalence of HIV, the type of injury and the response to an injury. Injuries may be classified as a 'definite case' where HIV seroconversion has been documented following a known occupational exposure. ${ }^{22}$ The second or 'possible' category implies that investigation of an HIV positive healthcare worker has revealed no identified risk factor for infection other than occupational exposure. ${ }^{22}$ The totals of 'definite' and 'possible' occupationally acquired HIV infections have amounted to 319 cases worldwide. ${ }^{23}$ These have comprised 102 definite (5 in UK) and 217 possible ( 8 in UK). There have been no definite but 9 possible cases of HIV occupational transmission in dental HCWs. ${ }^{23}$

\section{Chemoprophylaxis}

Guidelines on HIV post-exposure prophylaxis have recently been updated by the UK

- A deep injury: transmission through the skin by a needlestick, or a puncture wound or by contamination of a cut.

- Penetrating injury by a device visibly contaminated with blood.

- Injury with a needle that had previously been placed directly in the source patient's artery or vein.

- Exposure to a source patient with end stage HIV infection.

Source: Case-control study of HIV seroconversion in healthcare workers after percutaneous exposure to HIV infected blood - France, United Kingdom and United States, January 1988-August 1994. Anonymous MMWR 1995: 44; 929-933.

Health Departments. ${ }^{24}$ There are practical difficulties and substantial inconvenience to obtaining advice following a sharps exposure and, where necessary, HIV drug prophylaxis. Time is important and ideally prophylaxis should commence within 1 hour of the incident. ${ }^{24,25}$ The biological rationale for post exposure prophylaxis (PEP) relies on the time interval required for virus uptake, processing and incorporation after initial inoculation. The hope is that appropriate chemotherapy can prevent viral replication. PEP does not prevent infection but may prevent incorporation and immortalisation of viral DNA into host DNA.

There are several lines of evidence to support the use of anti-retroviral agents in PEP, such as data from animal studies ${ }^{26,27}$ as well as the use of zidovudine to decrease vertical HIV transmission in pregnancy. ${ }^{28}$ The original case control study of zidovudine prophylaxis following percutaneous injuries in HCWs showed a reduction in the rate of seroconversion of up to $79 \% .{ }^{29}$ Currently a triple combination regimen, usually employing zidovidine (Retrovir) with lamivudine (Epivir) and indinavir (Crixivan) for 4 weeks is used and is believed to be at least as effective. However, the use of PEP is not without drawbacks (and criticisms). There are now at least 15 anti-retroviral drugs available, but all have side effects. Particular problems include nausea, vomiting, anaemia, fatigue, insomnia and renal stone formation. ${ }^{24}$ Concerns about anti-viral drug resistance and drug over use thereby encouraging viral resistance are real. ${ }^{30}$ Furthermore if the virus has already undergone integration into the host genome the use of anti-retrovirals is then too late to be effective.

Many of these issues surrounding the management of sharps injuries in general dental practice will now be illustrated by means of two hypothetical case scenarios.

\section{Scenario I}

The time is 5.00pm on a Friday afternoon, prior to a bank holiday weekend! Following an inferior dental block a dentist accidentally sticks the needle into his thumb and notices blood accumulating under his glove. The patient is a 28-year-old male on his second visit to the practice.

\section{How should the incident be managed?}

First stop all operative procedures. Now identify and examine the wound. Then immediately institute some basic first aid, namely, wash but do not scrub the injury (Fig. 1). Ideally, the risk assessment should now be undertaken by a second competent HCW. However, this may be extremely difficult to undertake in some practices.

The first step in the assessment process is to assess the significance of the injury. This has been investigated by a number of studies $^{23,29}$ of occupationally acquired HIV infection. Most 'definite' cases have followed percutaneous exposure. ${ }^{23}$ Some percutaneous HIV exposures are of greater risk than others. Those factors identified by a case control study ${ }^{29}$ as high risk are listed in Table 1. The injury in this particular scenario is not high risk because the local anaesthetic needle was not placed directly into the source patient's artery or vein.

The next phase of assessment now determines the risk posed by the patient. This involves asking some highly personal and embarrassing questions (Table 2). Again this is best performed by a HCW not directly involved in the incident. Great tact is required. It may help to explain to the patient that there is no risk to her/him but there is a health concern for the injured 
HCW. The questions of a highly personal nature can be put in context by explaining that the Blood Transfusion Service routinely asks them of all blood donors. This may defuse any resentment.

The injured practitioner should now seek expert advice. ${ }^{25} \mathrm{~A}$ telephone number for sources of advice should be provided by the regional health board and usually includes the local accident and emergency department. It is helpful if your most recent hepatitis $B$ antibody titre is available to quote.

All source patients should be asked if they are willing to provide a sample of blood to test for BBVs, since a positive or negative result will determine the management of the dental HCWs injury, potentially over a period of 6 months. The appropriate person contacted for advice should take the blood sample. Undue pressure must not be applied to the patient to comply with this request. The result of the discussion should be recorded in the patient's notes.

When approached this patient fully co-operated and denied engaging in any high risk behaviour.

Provided the HCW's hepatitis B antibody titre is satisfactory (ie anti-HBs antibody titre of $>100 \mathrm{iu} / \mathrm{l}$ or 10-99 iu/l if last vaccine dose was within 2 years) and arrangements for venepuncture of the HCW and the patient has been made, then no further action is necessary at this point. However, it is a legal requirement to log the incident in the practice accident book. Furthermore the reporting of injuries and other occupational exposure under the Reporting of Injuries, Diseases and Dangerous Occurrences Regulations (RIDDOR) 1995 should also be undertaken. ${ }^{25}$ The practice dental team should discuss the incident and the means to reduce the risks of any repeat incident occurring should be implemented.

\section{Would management differ if the patient} declared that he belonged to one of the high risk groups highlighted in Table 2?

When the source patient is of unknown HIV status but is considered to have high risk factors, it is generally appropriate to commence combination anti-retroviral treatment prior to the result of a HIV test. Chemoprophylaxis should be recommended to exposed HCWs after a high risk incident. For exposures with a lower, but non-negligible risk, PEP may be offered (as in this case), balancing the risks of transmission with those of drug efficacy and toxicity. However, the risk in this case is of a lower order because, although the patient may have high risk factors, the nature of the injury was low risk. The needle had a narrow lumen, it had not been placed directly into a vein or artery and there was no visible contamination of the needle by the patient's blood. For exposures with negligible risk, PEP is not justified. It must be stressed that the initiation of PEP should be the responsibility of an expert in HIV disease and be based upon details provided by the HCW about the type of injury and nature of the source patient.

There is an obvious logistical problem for the individual dental practitioner in attempting to obtain this treatment after a significant exposure. This emphasises the need both for proper planning and for identification of sources of expert advice prior to occurrence of an accident. The risk of transmission of HIV by dental needlesticks is low, but the consequences may be serious and the circumstances are usually stressful. Practitioners who are at particularly high risk of HIV exposure because of their patient groups should be encouraged to consider in advance, their feelings around the issue of drug prophylaxis.

Work practices during the follow-up period About $95 \%$ of BBV infections will be detectable by the sixth month after exposure. Later, seroconversion is rare. Whilst awaiting serological follow up (retested at 6 weeks, 3 months and 6 months) a HCW need not avoid performing exposure prone procedures (EPP), that is, procedures where there is a risk that injury to the worker may result in the exposure of the patient's open tissues to the blood of the worker. ${ }^{25}$ This is because the combined risk of the HCW becoming occupationally infected and then transmitting to a patient during an EPP is too small to merit such a restriction. However, advice should be given about the advisability of safe sex and the avoidance of blood donation during the follow up period. In the unlikely event of seroconversion by the HCW to established HIV infection, the performance of EPPs (including dentistry) must then cease in accordance with recommendations. ${ }^{25}$

\section{Table 2}

\section{A list of questions to establish whether a patient is in a} high risk category for infection with a blood borne virus

I. Have you ever been told that you are positive for HIV/AIDS or hepatitis $\mathrm{B} / \mathrm{C}$ infection?

2. If you are a man: have you ever had sex, even safe sex, with another man?

3. Have you ever injected yourself with drugs? This includes body building drugs?

4. Have you ever lived in or visited Africa or any Far Eastern country and had sex with men or women living there or received hospital treatment?

5. Have you ever received a blood transfusion outside the UK? If yes where?

6. Have you been a prostitute at any time?

7. Have you ever had sex with a person in the above groups? 


\section{occupational health}

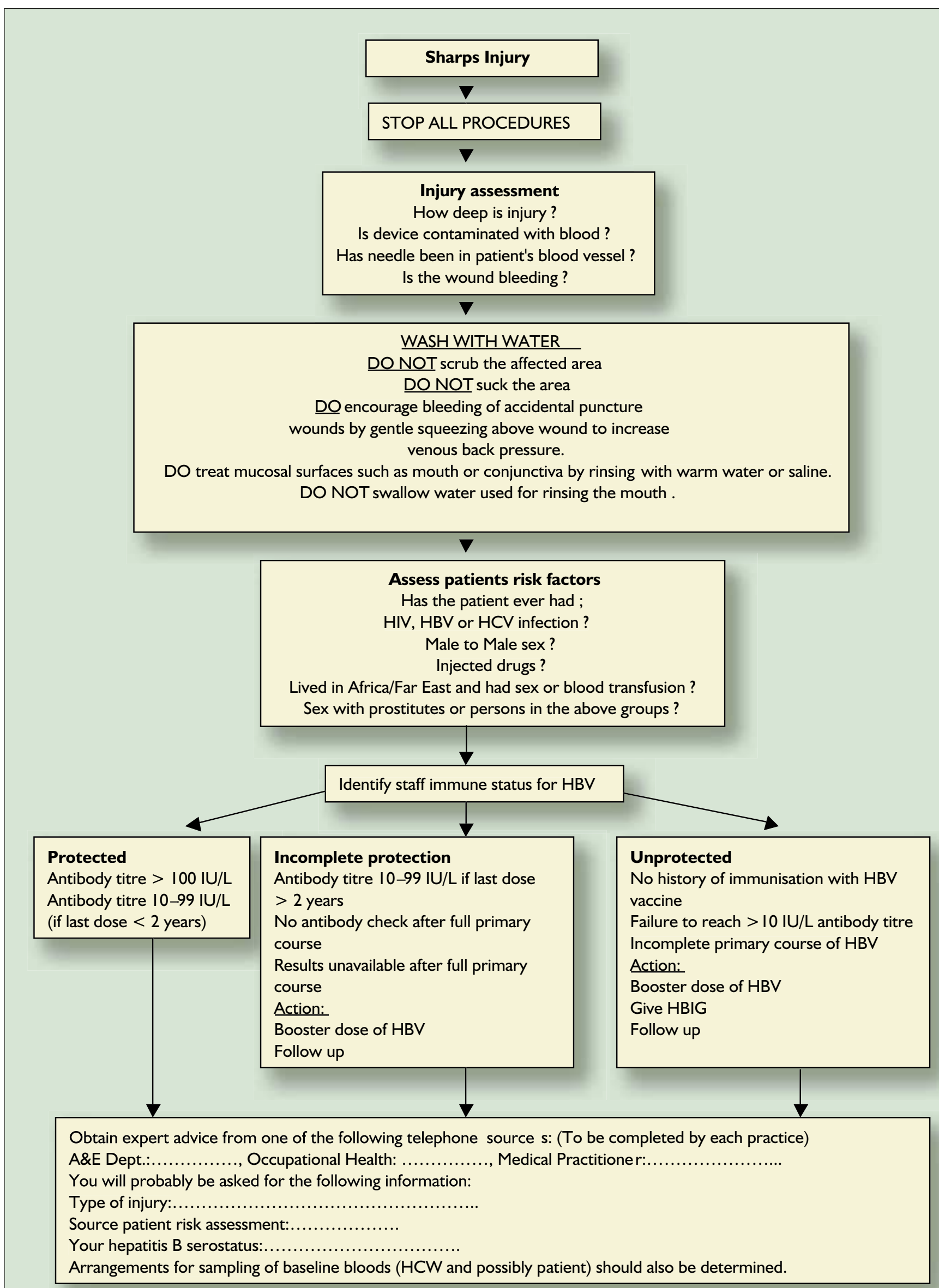

Fig. I First aid management of sharps injury 


\section{Scenario 2}

Your new dental nurse, whilst cleaning instruments prior to autoclaving, cuts her finger on a periodontal scaling instrument. How would you manage this accident?

Identify the wound and institute some basic first aid (Fig. 1). Next assess the significance of the injury. Although the practitioner should be in a position to assess the immediate incident, the necessity to obtain baseline blood samples means that expert advice should also be sought at this stage as outlined in Scenario 1.

During the risk assessment of this incident, your nurse informs you that she has only just started her hepatitis B immunisation course. There are now two actions that should be followed. First the dental nurse should receive a rapid course of active vaccination over the next 2 months. Second, hepatitis B immunoglobulin should be given within 48 hours.

After the initial first aid, you suddenly remember that the scaler may have been used on an intra-venous drug user (IVDU). Reviewing the patient's medical history reveals that he is hepatitis $C$ antibody positive. What do you do next?

Hepatitis $\mathrm{C}$ virus (HCV) is found in saliva but is most frequently acquired by direct blood to blood contact. The estimated risk of transmission after needlesticks is $1.8 \% .^{11}$ The commonest mode of transmission in the UK is the sharing of blood contaminated injecting equipment by IVDUs. ${ }^{10}$ Both sexual and perinatal transmission can occur but in general these are less efficient modes of transmission. No prophylactic measures involving drugs or immunoglobulin are presently available so first aid management is very important. It is also essential that a baseline blood sample be taken at the time of the injury. If an exposed staff member subsequently seroconverts then referral for specialist monitoring of liver function and assessment for antiviral therapies is recommended.

The patient is also in a high risk category for HIV infection, although the injury constitutes a low risk incident. However, the option of HIV prophylaxis should be dis-

- Staff training

- First aid procedures

- A definition of 'significant exposure'

- A means of assessing the risk status of the patient

- Source of emergency advice and subsequent support for the psychological consequences of the incident.

- Out-of-hours access

- Sites of starter packs of PEP drugs and/or hepatitis B prophylaxis

- Procedure following a sharps injury

- Arrangements for practice review after any exposure incident.

- Arrangements for follow-up visits, follow-up testing, record keeping and confidentiality

(Note much of this information should be available in the form of local policy documents issued by Regional Health Boards)

cussed between the dental nurse and expert advisor. It is unlikely that PEP would normally be recommended in this instance, although the nurse's view is very pertinent. Decisions about PEP during pregnancy are particularly difficult and should take account of the balance of the risks to the mother and her baby. It should not be withheld where the risks of HIV infection are thought to be significant.

Work practices for $\mathrm{HCW}$ infected with $\mathrm{HCV}$ To date there have been three reported instances of $\mathrm{HCW}$ to patient transmission of $\mathrm{HCV},{ }^{31-33}$ none of which were in dentistry, suggesting that the risk of transmission from HCW to patient is low. Based on this evidence, the UK Advisory Group on Hepatitis are recommending that HCWs with hepatitis $\mathrm{C}$ infection are not prevented from performing EPPs unless they have already been shown to transmit hepatitis $C$, but this advice is kept under constant review. However, a HCW with HCV infection should obtain advice from an occupational health unit to optimise precautions to reduce the potential risk of transmission during EPPs. Advice should also be obtained about local arrangements for the reporting, assessment and management of any incident in which patients appear to have been exposed to blood of an infected HCW.

\section{Development of a sharps/needlestick incident protocol}

So far, data have indicated that the risk of blood borne viral infections acquired in the dental environment is reassuringly low. However, it is difficult to be prescriptive about every possible scenario involving a sharps injury since so much depends on the type of injury and the source patient. It is important that a seamless procedure should develop from immediate first aid, through post exposure prophylaxis (for HBV and HIV infection) to arrangements for follow-up visits, followup testing and confidential record keeping. Medical supervision is best undertaken by an occupational health physician or, failing which, a local general medical practitioner. It is also important to remember that the oral cavity contains a diverse bacterial flora, which may act as a source of opportunistic pathogens to cause severe wound infections. Hence it is important that wounds are also treated appropriately for potential bacterial infections. The efficacy of personal protective equipment, especially gloves, in preventing exposure has frequently been questioned. Studies of the effect of latex gloves upon the volume of blood inoculated during needlestick injury have shown a significant benefit, reducing the volume of transferred blood by $46-86 \%{ }^{34}$

The best policy of all is to prevent sharps injuries. Thus all dental practices should have a written, relevant, up-to-date and easily accessible protocol that is understood by all practice personnel. Suggestions for such a practice protocol are illustrated in Table 3. The most important aspect of the prevention and management of sharps injuries is to undertake staff training. Regular staff training should focus on topics such as the avoidance of injuries, the use of heavy duty gloves and of eye protection whilst cleaning instruments or, preferably, use of ultrasonic cleaners with suitable detergents, and the immediate application of first aid treatment. 
This may require modification of current procedures and working practices. It is also useful to explore what action should be taken following possible exposure and indeed to undertake role-play in the proper first aid response to an injury. An HCW who is particularly at risk should be encouraged to consider in advance their attitudes to PEP, should an incident occur. It is also important to report all work-related injuries.

\section{Conclusion}

The risk of occupationally related blood borne viral infection from patient to dentist or vice versa is exceptionally low. The introduction of universal precautions and hepatitis B immunisation by the dental profession has done much to reduce the risks of such occupational infections. The implications of new anti-viral treatments and diagnostic techniques continue to unfold. It is important to keep abreast of these changes since they may impact on dental practice. However, despite this a situation may arise where a considerable degree of doubt exists about the most appropriate action to take, especially in the setting of general dental practice where expert advice may be particularly difficult to obtain. Written protocols should therefore be readily accessible within the practice to deal with such an eventuality. Finally, few other situations exist where the maxim that 'prevention is better than cure' applies more pertinently than that of needlestick injuries. Regular staff training will do much to reduce the physical and psychological consequences of such an incident.

1 Scheutz F, Mellbye M, Esteban J I et al. Hepatitis B virus infection in Danish dentists; a case control study and follow-up study. Am J Epidemiol 1988; 128: 190-196.

2 Porter S R, Scully C. HIV; the surgeons perspective. Br J Oral Max Surg 1994; 32: 222-230.

3 Cottone J A, Puttaiah R. Hepatitis B virus infection. Dent Clin North Am 1996; 40: 293-307.

4 Schiff E R, de Medina M D, Kline S N et al. Veterans administration cooperative study on hepatitis and dentistry. J Am Dent Assoc 1986; 113: 390-396.

5 Polakoff S. Acute viral hepatitis B; laboratory reports 1985-8. Comm Dis Report 1989; 26-29.
6 Gyawali P, Rice P S, Tilzey A J. Exposure to blood borne viruses and the hepatitis $\mathrm{B}$ vaccination status among healthcare workers in inner London. Occup Environ Med 1998; 55: 570-572.

7 Thompson S C, Norris M. Hepatitis B vaccination of personnel employed in Victorian hospitals: are those at risk adequately protected? Infect Control Hosp Epidemiol 1999; 20: 51-54.

8 Tatham D, Holden J. Hepatitis B vaccination for occupational risk: an audit in general practice. Community Dis Pub Health 1999; 2: 219-221.

9 Department of Health. Protecting Health Care Workers and Patients from Hepatitis B: Recommendations of the Advisory Group on Hepatitis. Department of Health, HSG(93)40, 1993. Addendum issued under cover of EL(96)77, 1996

10 Ramsay M E, Balogun M A, Collins M, Balraj V. Laboratory surveillance of hepatitis C virus infection in England and Wales: 1992 to 1996. Comm Dis and Pub Health 1998; 1: 89-94.

11 CDC. Recommendations for follow-up of HCW after occupational exposure to hepatitis C virus. MMWR Morb Mortal Wkly Rpt 1997; 46: 603-606.

12 Dore G J, Kaldor J M, McCaughan G W. Systematic review of role of polymerase chain reaction in defining infectiousness among people infected with hepatitis C virus. $B M J$ 1997; 315: 333-337.

13 Herbert A M, Walker C M, Davies K J et al. Occupationally acquired hepatitis $C$ virus infection. Lancet 1992; 339: 305.

14 Gerberding J L. Incidence and prevalence of human immunodeficiency virus, hepatitis $\mathrm{B}$ virus, hepatitis $\mathrm{C}$ virus and cytomegalovirus among health care personnel at risk for blood exposure: final report from a longitudinal study. J Infect Dis 1994; 170: 1410-1417.

15 Lodi G, Porter S R, Teo C G, Scully C. Prevalence of HCV infection in health care workers of a UK dental hospital. Br Dent J 1997; 183: 329-332.

16 Thomas D L, Factor S H, Kelen J D et al. Viral hepatitis in health care personnel at the John Hopkins Hospital. Archs Int Med 1993; 153: 1705-1712.

17 Thomas D L, Gruninger S E, Siew C et al. Occupational risk of hepatitis $\mathrm{C}$ infections among general dentists and oral surgeons in North America. Am J Med 1996; 100: 41-45.

18 PHLS AIDS and STD Centre-Communicable Disease Surveillance Centre and Scottish Centre for Infection \& Environmental Health. AIDS/HIV Quarterly Surveillance tables No. 46: 00/1 May 2000

19 Tokars J I, Marcus R, Culver D H et al. Surveillance of HIV infection and zidovudine use among health care workers after occupational exposure to HIV infected blood: the CDC Cooperative Needlestick Surveillance Group. Ann Intern Med 1993; 118: 913-919.

20 Ippolito G, Puro V, De Carli G and the Italian
Study Group on Occupational Risk of HIV infection. The risk of occupational human immunodeficiency virus infection in health care workers. Archs Intern Med 1993; 153: 1451-1458.

21 Anon. Needlestick transmission of HTLV-III from a patient infected in Africa. Lancet 1984; ii: $1376-1377$.

22 Evans B. Occupational acquisition of HIV infection among health care workers in the United Kingdom: data to June 1997. Comm Dis Pub Health 1998; 1: 103-107.

23 Public Health Laboratory Service AIDS \& STD Centre and Collaborators. Occupational transmission of HIV. Summary of published reports. Dec 1999 ed.

24 Expert Advisory Group on AIDS HIV. Postexposure prophylaxis: guidance from the UK Chief Medical Officers' Expert Advisory Group on Aids. London: Department of Health, 2000.

25 UK Health Department. Guidance for clinical health care workers: protection against infection with blood borne viruses. Recommendations of the Expert Advisory Group on AIDS and the Advisory Group on Hepatitis. 3rd edition. London: Department of Health 1998.

26 Black R J. Animal studies of prophylaxis. Am J Med 1997; 102: 39-44.

27 Böttiger A, Johansson N G, Samuelsson B et al. Prevention of simian immunodeficiency virus, SIVsm or HIV-2 infection in cynomolgus monkeys by pre and post-exposure administration of BEA-005. AIDS 1997; 11: 157-162.

28 Connor E M, Sperling R S, Gerber R et al. Reduction of maternal-infant transmission of human immunodeficiency virus type 1 with zidovudine treatment. N Engl J Med 1994; 331: 1173-1180.

29 Case-control study of HIV seroconversion in health-care workers after percutaneous exposures to HIV-infected blood: France, United Kingdom and United States; January 1988-August 1994. MMWR 1995; 44: 929-933.

30 Jochimsen E M. Failures of zidovudine postexposure prophylaxis in human immunodeficiency virus post-exposure management of health care workers. Am J Med 1997; 102: 2-5.

31 CDSC. Hepatitis C virus transmission from health care worker to patient. Comm Dis Rep CDR Wkly 1995; 5: 121.

32 Esteban J I, Gomez J, Martell M et al. Transmission of hepatitis $C$ virus by a cardiac surgeon. N Engl J Med 1996; 334: 555-560.

33 Duckworth G J, Heptonstall J, Aitken C. For the Incident Control Team and others: transmission of hepatitis $\mathrm{C}$ from a surgeon to a patient. Commun Dis Public Health 1999; 2: 188-192.

34 Mast S T, Woolwine J D, Gerberding J L. Efficacy of gloves in reducing blood volumes transferred during simulated needlestick injury. J Infect Dis 1993; 168: 1589-1592. 